\title{
PULMONARY RECONSTRUCTION IN THE ROSS PROCEDURE: COMBINED AUTOLOGOUS AORTIC AND POLYTETRAFLUOROETHYLENE VALVE
}

\author{
Masaaki Yamagishi, MD, Takeshi Emmoto, MD, Yukio Wada, MD, and Takahiro Oka, MD, Kyoto, Japan
}

Aortic root replacement with the pulmonary autograft is a valuable technique especially in children with the left ventricular outflow obstruction or a dilated aortic anulus, because it avoids use of a prosthetic valve and anticoagulation therapy. However, problems with durability and growth potential of the pulmonary autografts in the aortic position have been reported. ${ }^{1}$ The best material for reconstructing the right ventricular outflow tract (RVOT) also remains controversial. We describe a technique performed concomitantly with the Ross procedure, in which the RVOT was reconstructed with a tricuspid valve made of the autologous aortic noncoronary cusp and a bicuspid valve made of expanded polytetrafluoroethylene (ePTFE).

The patient was an 8-year-old girl, weighing $23 \mathrm{~kg}$, in New York Heart Association functional class II. The echocardiogram showed that the aortic valve had 3 cusps: a large mobile noncoronary cusp and small restrictive right and left cusps. All commissures were fused. Cardiac catheterization and cineangiocardiogram showed a pressure gradient of $80 \mathrm{~mm} \mathrm{Hg}$ between the left ventricle and ascending aorta and moderate aortic regurgitation. The aortic annular diameter was $19 \mathrm{~mm}$ ( $144 \%$ of normal value); the pulmonary annular diameter was $14 \mathrm{~mm}$ (106\% of the normal aortic annular value). Preoperatively, $400 \mathrm{~mL}$ of autologous whole blood was drawn and stored for postoperative transfusions, and recombinant epoetin alfa (Kirin Permacology, Tokyo, Japan) was administered. Through a median sternotomy, moderate hypothermic cardiopulmonary bypass $\left(28^{\circ} \mathrm{C}\right)$ was established. With the heart beating, the anterior and lateral aspects of the pulmonary artery were excised from the RVOT. The posterior aspect was excised after aortic crossclamping and administration of cold crystalloid cardioplegic solution, taking care to avoid the septal perforator coronary artery. The excised pulmonary autograft was preserved in cold saline solution. The ascending aorta was transected $5 \mathrm{~mm}$ above the sinotubular junction. The left and right coronary ostia were detached along the adjacent aortic wall. The right and left coronary cusps were hypoplastic and tightly adherent to a subvalvular fibrous ridge; neither

From the Department of Surgery II, Children's Research Hospital, Kyoto Prefectural University of Medicine, Kyoto, Japan.

Received for publication Aug 7, 1998; accepted for publication Aug 26, 1998.

Address for reprints: Masaaki Yamagishi, MD, Department of Surgery II, Children's Research Hospital, Kyoto Prefectural University of Medicine, Kawaramachi, Hirokoji, Kamikyo-ku, Kyoto 602-0841 Japan.

J Thorac Cardiovasc Surg 1998;116:1076-7

Copyright () 1998 by Mosby, Inc.

0022-5223/98 $\$ 5.00+0 \quad \mathbf{1 2 / 5 4 / 9 4 0 5 3}$ of the cusps was mobile. The free edge of the noncoronary cusp was slightly hypertrophied but sufficiently mobile. This cusp was harvested along with the adjacent aortic wall. The right side of the aortic fibrous ring of the noncoronary cusp was preserved to avoid injury to the atrioventricular conducting tissue beneath the anulus. After reconstruction of the aortic root with the pulmonary autograft, the noncoronary cusp was anastomosed directly to the septal aspect of the RVOT opening, and the adjacent autologous aortic wall was anastomosed to the distal pulmonary artery (Fig 1). A bicuspid, fanshaped valve made of a 0.1-mm-thick ePTFE membrane ${ }^{2 *}$ was anastomosed to a bovine pericardial patch with use of 60 monofilament running suture. The patch was cut to a width equal to the diameter of the neopulmonary anulus, which was $120 \%$ of the normal value. The width of each ePTFE cusp was one half that of the pericardial patch. The patch bearing the ePTFE valve was anastomosed to the anterior aspect of the neopulmonary trunk; thus the valve was placed at the same level as the original pulmonary anulus, facing the autologous noncoronary cusp. The operation required transfusion of the reserved autologous blood but no homologous blood. Postoperative echocardiography showed good function of each neopulmonary valve, including the ePTFE valve, and only minimal pulmonary insufficiency. There was no pressure gradient between the right ventricle and the neopulmonary artery; the right ventricular function was maintained satisfactorily. At 8-month follow-up, the patient is doing well; echocardiography showed that peak gradient across the neopulmonary valve was $10 \mathrm{~mm} \mathrm{Hg}$ and that each neopulmonary valve was functioning well with mild regurgitation.

Discussion. In RVOT reconstruction during the Ross procedure, interposition of a prosthesis between the RVOT and the distal pulmonary artery is necessary, because a direct anastomosis might induce bleeding caused by excessive tension on the anastomosis and compression on the left coronary artery behind the RVOT. A competent pulmonary valve for the new RVOT is also essential for preventing pulmonary insufficiency and right ventricular dysfunction. A cryopreserved aortic or pulmonary homograft is generally used for reconstruction, but reoperation because of early or late conduit failure is inevitable, especially in pediatric patients. ${ }^{3}$ Moreover, reducing the size of the homograft, which is often necessary in pediatric patients, may impair the valvular function. With our technique, the autologous noncoronary cusp, including the adjacent aortic wall that remains after resection of the coronary buttons, is used to reconstruct the posterior aspect of the

*PRECLUDE Pericardial Membrane; WL Gore \& Associates, Inc, Flagstaff, Ariz. 


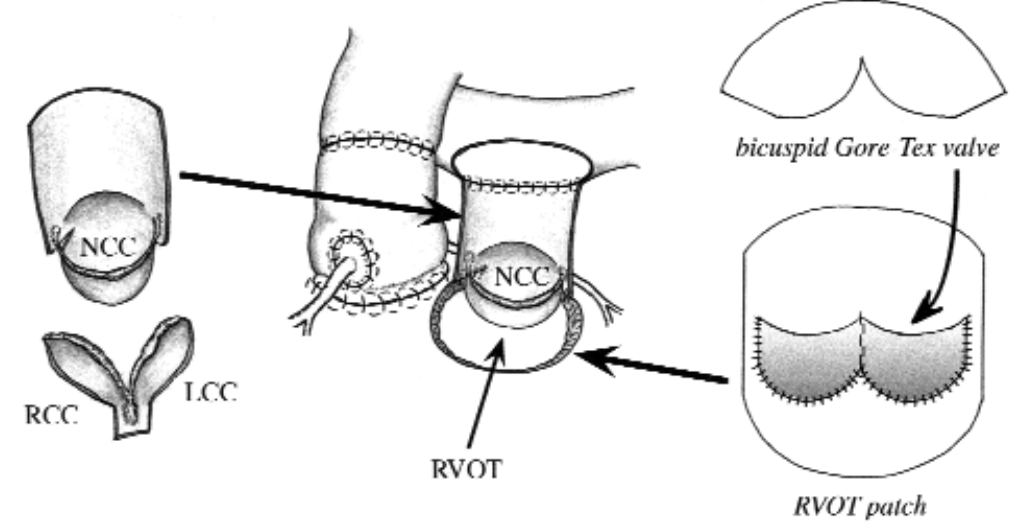

Fig 1. The operative technique includes reconstruction of the posterior wall of the RVOT with use of the noncoronary cusp (NCC) and the adjacent autologous aortic wall. The bicuspid, fan-shaped valve is made of a 0.1$\mathrm{mm}$-thick ePTFE membrane anastomosed to a bovine pericardial patch. The patch bearing the ePTFE valve is anastomosed to the anterior aspect of the RVOT. $R C C$, Right coronary cusp; $L C C$, left coronary cusp.

RVOT. The anterior aspect is covered with a bovine pericardial patch bearing a bicuspid ePTFE valve. The ePTFE valve is easily constructed in the operating room and tailored to the diameter of the RVOT and width of the autologous aortic wall of the individual patient. ${ }^{2}$ The valve is made of a membrane formed of ePTFE that has a microporous structure. The material does not calcify; thus it will retain flexible valvular function for the long term. ${ }^{4}$ To maintain valvular function, the ePTFE valve must be anastomosed at the same level as the original pulmonary anulus, facing the autologous noncoronary cusp. The growth potential of the RVOT will be retained because its posterior aspect consists of viable autologous aortic wall. Even when the noncoronary cusp cannot be used because of stenosis or hypoplasticity of the anulus, the aortic wall should be used for the posterior aspect of the RVOT. DeLeon and his colleagues ${ }^{5}$ described a procedure in which all 3 aortic cusps were reimplanted directly at the RVOT opening, and a prosthetic patch was anastomosed to the right and left coronary cusps. However, their technique is applicable only in patients without stenotic lesions. Furthermore, it may result in pulmonary incompetence because of the stretched, downwardly displaced neopulmonary anulus, and degenera- tion of the right and left cusps may occur because of the direct anastomosis with the prosthetic patch. Our procedure can be used in almost all patients with aortic incompetence and/or aortic stenosis who have a mobile noncoronary cusp.

\section{REFERENCES}

1. Schoof PH, Cromme-Dijkhuis AH, Bogers AJJC, et al. Aortic root replacement with pulmonary autograft in children. J Thorac Cardiovasc Surg 1994;107:367-73.

2. Yamagishi M, Kurosawa H. Outflow reconstruction of tetralogy of Fallot using a Gore-Tex valve. Ann Thorac Surg 1993;56: 1414-7.

3. Baskett RJ, Ross DB, Nanton MA, Murphy DA. Factors in the early failure of cryopreserved homograft pulmonary valves in children: Preserved immunogenicity? J Thorac Cardiovasc Surg 1996;112:1170-9.

4. Kurosawa H, Morita K, Yamagishi M, Shimizu S, Becker AE, Anderson RH. Conotruncal repair for tetralogy of Fallot: midterm results. J Thorac Cardiovasc Surg 1998;115:351-60.

5. DeLeon SY, Quinones JA, Miles RH, et al. Use of the native aortic valve as the pulmonary valve in the Ross procedure. Ann Thorac Surg 1995;59:1007-10. 